P-ISSN: 2541-6960; E-ISSN: 2549-8754

Yupa: Historical Studies Journal

Vol. 4 No. 1, 2020 (20-28)

http://jurnal.fkip.unmul.ac.id/index.php/yupa

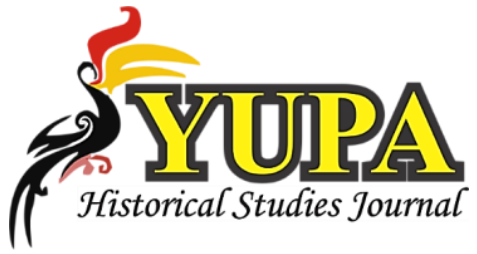

\title{
Penerapan Model Pembelajaran Jigsaw untuk Meningkatkan Hasil Belajar IPS
}

\author{
Agus Susilor, Yeni Asmara $^{2}$ \\ 1STKIP PGRI Lubuklinggau, Lubuklinggau, Indonesia \\ 2 STKIP PGRI Lubuklinggau, Lubuklinggau, Indonesia \\ 1agussusilo594@yahoo.co.id, 2yeni.stkip@gmail.com
}

\begin{tabular}{ccc}
\hline Received & Accepted & Published \\
$06 / 07 / 2020$ & $25 / 07 / 2020$ & $10 / 09 / 2020$ \\
\hline
\end{tabular}

Abstract This research while such with lack of learning model applied by teachers in junior high school. Observations discovered that learning by teachers on the subjects of a common social studies impressed and boring. Because this, then become fewer interesting students learning. Of course, learning outcomes students being declined and in need of renewal for teachers give kind of classroom. The purpose of this research is knowing the learning model jigsaw in social studies improve learning outcomes. Methods used in research is the methodology quantitative experiment with the apparent research. The sample used in this research is the Class VIII with the number of students 261 someone else by samples for learning model Jigsaw. The results of the study show results that that t count $(2,270)>t$ table $(1,706)$ This means Ho rejected and Ha received. In addition, jigsaw kind of classroom learning is considered very effective applied in social studies at school. Significantly bring a positive impact on learning. Teachers can of covering jigsaw learning model with medium learning or other kind of classroom. Drawing conclusions from the study that kind of classroom jigsaw is very effective applied in junior high school. Learning science to set an example of social model jigsaw most effective and interesting students.

Keywords: learning model, Jigsaw Model, Social Studies Learning

Abstrak Penelitian ini dilatarbelakangi dengan minimnya model pembelajaran yang diterapkan oleh guru di sekolah menengah pertama. Hasil observasi diketahui bahwa pembelajaran yang dilakukan guru pada mata pelajaran IPS terkesan biasa saja dan membosankan. Oleh karena hal tersebut, maka pembelajaran menjadi kurang menarik siswa. Tentu imbasnya hasil belajar siswa menjadi menurun dan membutuhkan pembaharuan bagi model pembelajaran yang diberikan guru. Tujuan penelitian ini adalah mengetahui penerapan model pembelajaran Jigsaw dalam meningkatkan hasil belajar IPS. Metode yang digunakan dalam penelitian ini adalah metode penelitian kuantitatif dengan jenis penelitiannya eksperimen semu. Sampel yang digunakan dalam penelitian ini adalah kelas VIII. 1 dengan jumlah siswa sebanyak 26 orang yang dijadikan sampel untuk model pembelajaran Jigsaw. Hasil dari penelitian ini menunjukkan hasil bahwa bahwa thitung $(2,270)>$ ttabel $(1,706)$. Hal ini berarti Ho ditolak dan Ha diterima. Selain itu, model pembelajaran Jigsaw dinilai sangat efektif diterapkan dalam pembelajaran IPS di sekolah. Peningkatan yang signifikan memberikan dampak positif bagi pembelajaran. Guru dapat mengkreasikan model pembelajaran Jigsaw dengan media pembelajaran atau model pembelajaran lainnya. Simpulan dari penelitian ini bahwa model pembelajaran Jigsaw sangat efektif diterapkan di sekolah menengah pertama. Pembelajaran IPS menjadi contoh penerapan model Jigsaw yang paling efektif dan menarik siswa.

Kata kunci: model pembelajaran, model jigsaw, Belajar IPS 


\section{PENDAHULUAN}

Undang-undang Sistem Pendidikan Nasional No. 20 tahun 2003 menyatakan bahwa pendidikan nasional bertujuan untuk mengembangkan potensi peserta didik agar menjadi manusia yang beriman dan bertaqwa kepada Tuhan Yang Maha Esa, berakhlak mulia, sehat, berilmu, cakap, kreatif, mandiri dan menjadi warga demokratis serta bertanggung jawab. Undang-undang sistem pendidikan nasional merumuskan demikian karena pendidikan merupakan salah satu bentuk pembangunan bangsa dalam menciptakan sumber daya manusia yang berkualitas sebagai penentu masa depan bangsa (Khayati et al., 2020).

Kegiatan awal dalam dunia pendidikan adalah melaksanakan proses belajar. Adanya kegiatan proses belajar mengajar ini, diharapkan dapat menghasilkan prestasi belajar yang lebih baik. Para siswa diharapkan mengalami peningkatan dalam segi pemahaman, pengetahuan, keterampilan, nilai, dan sikap. Hasil akhir dalam mengikuti kegiatan belajar mengajar di sekolah, merupakan faktor penting dalam dunia pendidikan (Ismail, Zulfikar \& Parwati, 2011).

Dalam dunia pendidikan, indikator mutu dan kualitas dalam dunia pendidikan adalah mampu meningkatkan harkat dan martabat manusia. Salah satu faktor yang menjadikan pendidikan berhasil adalah peserta didik mampu menguasai materi yang didapatkan dibangku sekolah, sekaligus mampu mengaplikasikannya didunia kerja setelah lulus sekolah (Handayani, 2018).

Guru merupakan elemen terpenting dalam sebuah sistem pendidikan, proses belajar siswa sangat dipengaruhi oleh persepsi siswa terhadap guru. Kepribadian guru yang perhatian, hangat, suportif, dan pemberi semangat diyakini bisa member motivasi kepada siswa yang dapat meningkatkan prestasi belajar. Kompetensi guru bukan hanya menguasai apa yang harus diajarkan, tetapi bagaimana cara memberikan materi pelajaran kepada siswa agar pembelajaran menjadi lebih menarik, menyenangkan, dan siswa menjadi semakin termotivasi ketika mengikuti proses pembelajaran (Wasiso, Sukardi and Winarsih, 2020).

Guru merupakan faktor yang paling penting dalam meningkatkan kualitas sumber daya manusia dalam hal ini ialah siswa sebagai penerima informasi maupun yang bertindak sebagai salah satu elemen pelengkap dalam proses pembelajaran di sekolah. Pembelajaran saat ini ditekankan agar tidak hanya terfokus pada teacher centered akan tetapi student centered. Sikap sosial siswa pada pelajaran sejarah dianggap penting karena sejarah merupakan pelajaran dari ilmu sosial yang menekankan dan menanamkan nilai-nilai persatuan dan kesatuan (Wasiso, Sukardi and Winarsih, 2020).

Pendidikan merupakan faktor yang sangat penting dalam kehidupan manusia dan tidak dapat dipisahkan antara satu dengan yang lainnya. Oleh karena itu, dalam setiap aspek kehidupan manusia baik secara pribadi dan kelompok pendidikan wajib dilaksanakan. Sehubungan dengan 
itu, salah satu upaya dalam rangka menciptakan manusia yang berkualitas adalah dengan pendidikan (Yasri, Andi Ali Imran, dkk, 2017).

Saat ini banyak problem dalam proses pembelajaran yang dilakukan oleh guru dikarenakan Kenyataan di atas menunjukkan bahwa kemampuan berpikir tinggi dalam belajar IPS masih belum sesuai dengan apa yang diharapkan kurikulum. Siswa sangat jarang mengajukan pertanyaan pada guru sehingga guru asyik sendiri menjelaskan apa yang telah disiapkannya, dan siswa hanya menerima saja yang disampaikan oleh guru. Pembelajaran cenderung terjadi dalam satu arah, aktivitas pembelajaran lebih banyak guru dibanding interaksi di antara siswa (Burais, Fona Fitry, dkk, 2015).

Proses belajar mengajar itu dipengaruhi oleh beberapa kompenen utama yang saling berkaitan diantaranya guru, siswa dan model pembelajaran yang digunakan kompenenkompenen tersebut memegang peranan penting dalam menentukan keberhasilan proses belajar megajar, sehingga akan mempengaruhi prestasi belajar siswa. Selain itu juga di pengaruhi oleh faktor-fakor yang lain misalnya motifasi belajar, tingkat intelejensi siswa, fasilitas belajar yang tersedia, atau sarana dan prasarana, kurikulum, media pembelajaran dan sebagainya (Suparman, dkk, 2014).

Menurut (Rosyidah, 2016), untuk meningkatkan sebuah mutu pendidikan, perlu didukung oleh sebuah pembaharuan yang baik dibidang pendidikan. Hal ini sangat perlu dilakukan karena berkaitan dengan peningkatan kualitas pembelajaran yaitu pembaharuan pendekatan atau peningkatan relevansi model mengajar. Sebuah model pembelajaran dapat dikatakan apabila dalam prosesnya mampu menjadikan siswa mencapai tujuan pendidikan.

Menurut (Daryanto \& Rahardjo, Muljo, 2012), keterlibatan siswa dalam belajar sangat erat kaitannya dengan sifat peserta didiik, dilihat dari aspek kognitif yang meliputi kecerdasan dan bakat, maupun yang bersifat afektif seperti motivasi dan rasa percaya diri.

Penerapkan model pembelajaran yang tepat dalam proses mengajar akan dapat menarik minat dan motivasi peserta didik untuk belajar, untuk itu perlu ada usaha-usaha dari semua pihak terutama guru dan peserta didik dalam mewujudkannya. Menurut (Suprihatin, 2017), Pembelajaran kooperatif tipe Jigsaw adalah pembelajaran yang dilakukan dengan bentuk membagi beberapa kelompok yang ada dengan materi yang berbeda-beda. Dalam model Jigsaw sendiri, setiap kelompok memiliki tanggung jawab terhadap kelompoknya sendiri dan kelompok lainnya.

Pada umumnya, model pembelajaran tipe Jigsaw dapat membawa banyak pengaruh dalam pembelajaran IPS di Sekolah Menengah Pertama. Hal ini diketahui pada saat peneliti melaksanakan observasi maupun penelitian. Saat dilaksanakan observasi, siswa sangat antusias dengan model pembelajaran Jigsaw. Begitu juga saat dilaksanakan penelitian, siswa sangat antusias dan mengikuti kegiatan pembelajaran dengan baik. 
Model pembelajaran dengan melalui pendekatan Jigsaw merupakan suatu pendekatan pembelajaran yang menggabungkan berbagai potensi yang dimiliki siswa untuk membangkitkan keinginan belajar yang kuat untuk peningkatan motivasi belajar (Pontoh, Hanafi, dkk, 2016).

Menurut (Hamdani, 2011), para siswa ini nantinya akan bekerja sama untuk menyelesaikan tugas kooperatif yang tersusun dalam: (a) belajar dan menjadi ahli dalam subtopic bagiannya; (b) merencanakan cara mengajarkan untuk menjadi dalam subtopic bagiannya kepada anggota kelompoknya. Oleh karena hal tersebut, setiap siswa yang tergabung dalam kelompok harus menguasai topic secara keseluruhan.

Model pembelajaran Jigsaw menuntut siswa untuk belajar IPS dengan aktif dan antusias dalam mengikuti pembelajaran. Pengunaan model pembelajaran Jigsaw juga disampaikan dengan materi IPS yang menarik agar peserta didik mendapatkan ilmu dan pengetahuan yang baru. Siswa yang aktif setelah menerapan model Jigsaw akan menambah positif minat belajar IPS di Sekolah.

\section{METODE}

Metode penelitian yang dijadikan rujukan dalam penelitian ini adalah metode kuantitif. Sedangkan jenis penelitian ini, adalah penelitian eksperimen semu atau Semu Eksperimen Design. Dalam kajian penelitian ini, masih terkena pengaruh variabel dari luar yang terkait penelitian ini (Syaiful, 2010).

Jumlah populasi dalam penelitian ini dapat dilihat dari tabel 1.

Tabel 1. Populasi Penelitian

\begin{tabular}{ccccc}
\hline No & Kelas & Laki-Laki & Perempuan & Jumlah Siswa \\
\hline 1 & VIII. 1 & 10 & 16 & 26 \\
2 & VIII. 2 & 11 & 15 & 26 \\
& Jumlah & 21 & 21 & 52 \\
\hline
\end{tabular}

Sedangkan sampel dalam penelitian ini diambil dari kelas eksperimen yaitu di kelas VIII. 1 dengan jumlah siswa sebanyak 26 orang. Hal ini berdasarkan keinginan peneliti bahwa kelas yang didesain untuk penelitian merupakan kelas desain eksperimen semu. Menurut (Arikunto, Suharsimi, 2012), desain eskperimen dapat dijabarkan dalam table 2.

Tabel 2. Desain Eksperimen

\begin{tabular}{cccc}
\hline Group & Pretest & Treatment & Posttest \\
$\mathrm{A}$ & $\mathrm{O}_{1}$ & $\mathrm{X}$ & $\mathrm{O}_{2}$ \\
\hline
\end{tabular}


Data yang didapatkan dalam penelitian ini, dianalisis untuk mengetahui pengaruh dari model pembelajaran Jigsaw dengan analisis data kuantatif. Langkah-langkah dalam analisis data tersebut, yaitu:

$$
\overline{\mathrm{x}}=\sum_{\mathrm{n}} \times 1 \quad s=\sqrt{\sum \frac{\left(\times 1-\bar{x}^{2}\right.}{(n-1)}}
$$

Uji normalitas dalam penelitian ini adalah untuk mengetahui kenormalan data yang didapatkan. Rumus yang rumus yang digunakan adalah X² (Chi Kuadrat), yaitu:

$$
x^{2}=\sum\left(\frac{f_{0}-f_{h}}{f_{l h}}\right)
$$

Selanjutnya data yang diperoleh $\mathrm{X}^{2}$ hitung dibandingkan, dimana $\mathrm{X}^{2}$ tabel dengan tingkat taraf kepercayaan $5 \%$ dan $\mathrm{dk}=\mathrm{j}-1$. Sehingga $\mathrm{j}$ adalah banyaknya kelas interval. Jika $\mathrm{X}^{2}$ hitung < $\mathrm{X}^{2}$ tabel. Selanjutnya dapat disimpulkan bahwa data berdistribusi normal, dan data lainnya dinyatakan data tidak dapat berdistribusi secara normal.

Uji t dilakukan untuk mendapatkan data yang benar dalam penelitian eksperimen ini. akhirnya didapatkan perbedaan antara nilai pre-test dengan nilai post tes secara signifikansi (Sugiyono, 2015). Rumus dalam hipotesis penelitian eksperimen ini adalah sebagai berikut:

$$
t=\frac{x-\mu o}{s}
$$

Uji hipotesis tersebut didapatkan jika hipotesis nol $\left(\mathrm{H}_{0}\right)$ dan hipotesis alternatif $\left(\mathrm{H}_{\mathrm{a}}\right)$, yang dapat dilihat sebagai berikut:

$$
\begin{aligned}
& \mathrm{H}_{0} \quad \text { : Model pembelajaran Jigsaw tidak dapat menuntaskan hasil belajar IPS } \\
& \mathrm{H}_{\mathrm{a}} \quad \text { : Model pembelajaran Jigsaw dapat menuntaskan hasil belajar IPS }
\end{aligned}
$$

\section{RESULT AND DISCUSSION / HASIL DAN PEMBAHASAN}

Dalam penelitian ini, dimulai dengan uji statistik yang meliputi uji normalitas dan uji $\mathrm{T}$ untuk mengetahui hasil dari efektifitas model pembelajaran Jigsaw. Untuk uji normalitas dilakukan untuk melihat seberapa besar pengaruh dari distribusi nilai tersebut bernilai normal atau tidak. Hasil uji normalitas dapat dilihat pada 3. 
Tabel 3. Hasil Uji Normalitas

\begin{tabular}{ccccc}
\hline Tes & $\mathbf{X}^{2}$ hitung & $\mathbf{d k}$ & $\mathbf{X}^{2 \text { tabel }}$ & Kesimpulan \\
Pre-test & 9,3181 & 5 & 11.070 & Normal \\
Post-test & 5,1288 & 5 & 11.070 & Normal \\
\hline
\end{tabular}

Setelah diketahui data uji normalitas, maka selanjutnya dilakukan uji T, untuk menganalisis data hasil penelitian tersebut. Langkah awal dalam penelitian ini tentunya tidak lepas dari uji normalitas antara pre tes dan post tes. Selanjutnya dilakukan uji hipotesis terkait data yang didapat dalam penelitian.

Kriteria pengujiannya adalah $\mathrm{H}_{0}$ diterima jika $t_{\text {hitung }}<t_{\text {tabel }}$ dan $\mathrm{H}_{\mathrm{o}}$ ditolak jika $t_{\text {hitung }}>t_{\text {tabel }}$ saat signifikasi, yaitu $\alpha=0,05$ dengan $\mathrm{dk}=\mathrm{n}-1$. Sehingga dapat dijabarkan dalam rekapitulasi hasil uji t pre-test dan post tes sebagai berikut:

Tabel 4. Hasil Uji t

\begin{tabular}{cccc}
\hline $\mathbf{t}_{\text {hitung }}$ & $\mathbf{d k}$ & $\mathbf{t}_{\text {tabel }}$ & Kesimpulan \\
2,270 & 25 & 1,706 & $\mathrm{H}_{\mathrm{o}}$ ditolak dan $\mathrm{H}_{\mathrm{a}}$ diterima \\
\hline
\end{tabular}

Setelah dianalisis secara seksama dengan baik, diperoleh bahwa $t_{\text {hitung }}=2,270$. Selanjutnya $t_{\text {hitung }}$ dibandingkan dengan nilai $t_{\text {tabel }}$ pada daftar distribusi $t$ dengan derajat kebebasan $\mathrm{dk}=\mathrm{n}-1=26-1=25, \alpha=0,05 \mathrm{t}_{\text {tabel }}=1,706$. Maka dapat diketahui bahwa $\mathrm{t}_{\text {hitung }}(2,270)$ $>t_{\text {tabel }}(1,706)$. Hal ini berarti $H_{o}$ ditolak dan $H_{a}$ diterima. Setelah melalui proses uji t tersebut, maka dapat disimpulkan bahwa uji hipotesis ini dapat diterima kebenarannya dan model Jigsaw dapat menuntaskan hasil belajar IPS siswa SMP.

Model pembelajaran kooperatif adalah berusaha untuk merumuskan tujuan dalam dunia pendidikan melalui beberapa penekanan untuk menumbuhkan sikap yang baik. Pembelajaran kooperatif berusaha merekontruksikan kegiatan belajar mengajar. strategi pembelajaran kooperatif yang digunakan dalam menunjang kegiatan proses belajar mengajar dilakukan secara berkala. Model pembelajaran koperatif juga disebut sebagai model pembelajaran yang menentukan dalam kegiatan pembelajaran. Pembelajaran kooperatif akan membentuk sikap dan intektual yang bagus serta menumbuhkan keberhasilan yang besar dalam pendidikan (Susilo, Agus, 2019).

Guru yang mampu menghadirkan peserta didik untuk mendidik mereka sendiri, dengan mampu memberdayakan peserta didik secara efektif yang mampu mendorong peserta didik untuk menggunakan sumber-sumber belajar secara efektif, sehingga mereka mampu untuk menggunakan seluruh hasil belajar secara produktif. Pembelajaran yang berbasis belajar aktif juga harus dipahami sebagai suatu proses yang mengajak peserta didik untuk bekerjasama dalam 
rangka membantu mereka dalam mengubah pemahaman tentang materi pelajaran yang sedang dipelajari. Tentunya hal tersebut diawali dengan mengubah pemikiran siswa, dan menciptakan suasana belajar kondusif yang menyenangkan (Joyoatmojo, Soetarno, 2011).

Menurut Sanjaya dalam (Susilo, 2019), melaksanakan pembelajaran adalah sebagai usaha yang baik dalam mengembangkan kemampuan yang dimiliki oleh siswa. Pengembangan diri siswa dari kognitif, afektif, dan psikomotor harus berkesinambungan untuk dikembangkan. Model pembelajaran Jigsaw adalah solusi yang baik dalam mendukung pembelajaran abad 21 saat ini. penggunaan metode pembelajaran tidak hanya menyangkut diskusi saja, namun juga pendalaman materi terus dikembangkan dengan baik. Siswa mampu mengungkapkan ide-idenya yang membangun dan menjadikan siswa untuk bersikap jujur, tenggang rasa, dan sebagainya.

Model pembelajaran kooperatif tipe Jigsaw adalah model pembelajaran kooperatif yang memaksimalkan proses pembelajaran dengan adanya tim ahli. Sistem pengelompokan/tim kecil, yaitu antara 4-6 orang yang mempunyai latar belakang kemampuan akademik, jenis kelamin, ras atau suku yang berbeda (heterogen). Setiap siswa di dalam kelompok memiliki keahlian akan sub materi yang sedang dipelajari dan memiliki tanggung jawab untuk membagikannya dengan anggota lain dalam satu kelompok. Setiap siswa dalam satu kelompok tidak memiliki rasa malu untuk bertanya karena yang menjadi gurunya adalah temannya sendiri (Mastati. Eliseri, 2017).

Pembelajaran dengan menggunakan Jigsaw melibatkan semua peserta didik yang ada di kelas. Tujuan dari metode ini adalah mengembangkan kerja tim, ketrampilan belajar kooperatif dan penguasaan materi. Maka siswa akan selalu aktif dan menambah kualitas prestasi belajarnya, guru dapat memonitor pemahaman peserta didik, pembelajaran bisa lebih terarah, dan juga peserta didik bisa mengembangkan kemampuan diri sendiri dengan cara diskusidiskusi dan latihan soal (Juwahir \& Subagyo, 2018).

Seorang guru dalam mengajar harus pandai mengatur waktunya dan berpedoman dengan RPP. Guru harus menggunakan pendekatan yang sesuai dengan keadaan siswa di sekolah tersebut. Dalam penelitian ini, peran guru membagi siswa dengan beberapa kelompok agar pembelajaran dapat menjadi kondusif. Hal ini dilakukan agar siswa memiliki pola pikir yang baik untuk berkembang secara aktif dan kreatif dalam mengikuti pembelajaran. Dalam mengikuti pelajaran IPS yang memiliki materi sangat banyak dan harus dikembangkan, biasanya guru membagi dalam beberapa kelompok. Setiap kelompok akan memecahkan sebuah permasalahan dari materi tersebut secara bersama-sama dengan kelompoknya (Daryanto \& Rahardjo, Muljo, 2012).

Dalam menerapkan model pembelajaran Jigsaw, guru membagi kelas-kelas yang besar menjadi beberapa kelompok yang kecil. Tujuannya adalah untuk mempermudahkan dalam pembelajaran. Di dalam kelompok sendiri, masing-masing memiliki tugas dan tanggung jawab bersama yang harus dilaksanakan. Disini, siswa bekerja sama secara berkelompok untuk 
menyelesaikan tugas kooperatifnya, yang meliputi: (a) belajar dan menjadi ahli dalam sub topic bagiannya; (b) merencanakan cara mengajarkan subtopik bagian dari kelompok tersebut. Tanggung jawab dan kewajiban setelah dibagi oleh guru harus dilaksanakan dengan sangat baik oleh siswa (Hamdani, 2011).

Proses pembelajaran dengan model Jigsaw dapat digunakan untuk meningkatkan pembelajaran individu atau kelompok. Selama proses pembelajaran dengan model Jigsaw ini, siswa dapat menciptakan hasil berupa pengembangan materi secara individu untuk menunjukkan bahwa mereka telah mempelajari materi sepanjang proses berpikir, belajar, dan mengikuti pembelajaran dari gurunya. Siswa antar kelompok juga diperbolehkan memberikan komentar terkait materi dari teman kelompok lain, namun sifatnya pertanyaan yang membangun (Sharan, Shlomo, 2009).

\section{KESIMPULAN}

Penerapan model pembelajaran Jigsaw untuk meningkatkan hasil belajar IPS dapat diperoleh hasil $t_{\text {hitung }}=2,270$. Selanjutnya $t_{\text {hitung }}$ dibandingkan dengan nilai $t_{\text {tabel }}$ pada daftar distribusi t dengan derajat kebebasan $\mathrm{dk}=\mathrm{n}-1=26-1=25, \alpha=0,05 \mathrm{t}_{\text {tabel }}=1,706$. Maka dapat diketahui bahwa $t_{\text {hitung }}(2,270)>t_{\text {tabel }}(1,706)$. Hal ini berarti $H_{o}$ ditolak dan $H_{a}$ diterima. Maka model pembelajaran Jigsaw berhasil dapat meningkatkan hasil belajar IPS di sekolah. Perlu dipahami saat ini, guru harus lebih aktif dan kreatif untuk mengembangkan ide-ide cemerlangnya untuk kemajuan dunia pendidikan.

Model Jigsaw adalah salah satu model pembelajaran yang efektif untuk dilaksanakan di sekolah menengah pertama pada mata pelajaran IPS. Namun pengembangan model pembelajaran juga dapat dilakukan lebih kuat kembali untuk menghasilkan pembelajaran yang menarik dan menumbuhkan semangat belajar siswa.

\section{REFERENSI}

Arikunto, Suharsimi (2012) Prosedur Penelitian Suatu Pendekatan Praktik. Jakarta: Rineka Cipta.

Burais, Fona Fitry, dkk (2015) 'Penerapan Model Pembelajaran Kooperatif Tipe Jigsaw dalam Meningkatkan Kemampuan Pemahaman dan Komunikasi Matematis Siswa Sekolah Menengah Atas', Jurnal Didaktik Matematika, 2(2), pp. 84-94.

Daryanto \& Rahardjo, Muljo (2012) Model Pembelajaran Inovatif. Yogyakarta: Gava Media.

Hamdani (2011) Strategi Belajar Mengajar. Bandung: Pustaka Setia.

Handayani, E. S. (2018) 'Penerapan Model Pembelajaran Kooperatif Tipe Jigsaw dengan Peta Konsep Pada Materi Persamaan Kuadrat Ditinjau dari Sikap Ilmiah Peserta Didik Kelas X SMA di Kabupaten Kudus', Jurnal Pendidikan Matematika, 1(17-27).

Ismail, Zulfikar \& Parwati, L. (2011) 'Pengaruh Metode Pembelajaran Kooperatif Tipe Jigsaw Terhadap Prestasi Belajar Mahasiswa: Sebuah Eksperimen Semu', Akuntansi 
Multiparadigma, 2(3), pp. 472-479.

Joyoatmojo, Soetarno (2011) Pembelajaran Efektif pembelajaran yang membelajarkan. Surakarta: UNS Press.

Juwahir \& Subagyo (2018) 'Penerapan Metode Jigsaw Guna Meningkatkan Motivasi dan Hasil Belajar Pada Mata Pelajaran Teknologi Dasar Otomotif', Jurnal Taman Vokasi, 6(1), pp. 4652.

Khayati, N. A. et al. (2020) 'Peranan Guru Dalam Pendidikan Inklusif Untuk Pencapaian Program Tujuan Pembangunan Berkelanjutan ( SDG's ) The Role of Teachers in Inclusive Education for Achieving the Sustainable Development Goals ( SDG 's ) Program', Jurnal Komunikasi Pendidikan, 4(1), pp. 55-61.

Mastati. Eliseri (2017) 'Penerapan Model Pembelajaran Kooperatif Tipe Jigsaw untuk Meningkatkan Hasil Belajar Sejarah Siswa', Jurnal Pendidikan Ilmu-Ilmu Sosial, 9(2), pp. 246-254.

Pontoh, Hanafi, dkk (2016) 'Penerapan Model Pembelajaran Jigsaw Untuk Meningkatkan Hasil Belajar Ilmu Pengetahuan Sosial (IPS) Siswa Kelas V SD Inpres Salabenda Kecamatan Bunta', Jurnal Kreatif Tadulako, 4(11), pp. 200-209.

Rosyidah, U. (2016) 'Pengaruh Model Pembelajaran Kooperatif Tipe Jigsaw Terhadap Hasil Belajar Matematika Siswa Kelas VIII SMP Negeri 6 Metro', Jurnal SAP, 1(2), pp. 115-124.

Sharan, Shlomo (2009) Cooperatif Learning Inovasi Pengajaran dan pembelajaran untuk memacu keberhasilan siswa di kelas. Yogyakarta: Imperium.

Sugiyono (2015) Metode Penelitian Kuantitatif, Kualitatif, dan R \& D. Yogyakarta: Alfabeta.

Suparman, dkk (2014) 'Penerapan Model Pembelajaran Kooperatif Tipe Jigsaw Untuk Meningkatkan Aktivitas dan Hasil Belajar IPA Pada Konsep Pencemaran Lingkungan', Jurnal ßIOêduKASI, 3(1), pp. 293-298.

Suprihatin, S. (2017) 'Penggaruh Model Pembelajaran Jigsaw Terhadap Hasil Belajar Studi Masyarakat Indonesia Mahasiswa', Jurnal Promosi: Jurnal Pendidikan Ekonomi Um Metro, 5(1), pp. 84-94.

Susilo, Agus (2019) Strategi Pembelajaran Kreatif \& Inovatif di Perguruan Tinggi. Cirebon: Nusa Litera Inspirasi.

Susilo, A. \& I. (2019) 'Peran Guru Sejarah dalam Pembentukan Pendidikan Karakter Anak Era Globalisasi', IJSSE: Indonesian Journal of Social Science Education, 1(2), pp. 171-180.

Syaiful (2010) Belajar dan Pembelajaran. Semarang: CV. IKIP Semarang Press.

Wasiso, A. J., Sukardi, S. and Winarsih, M. (2020) 'Pengaruh model pembelajaran dan sikap sosial terhadap hasil belajar sejarah siswa SMA The effect of learning models and social attitudes on student history learning outcomes', Jurnal Penelitian Ilmu Pendidikan, 13(1), pp. 31-40.

Yasri, Andi Ali Imran, dkk (2017) 'Penerapan Model Pembelajaran Kooperatif Tipe Jigsaw Untuk Meningkatkan Prestasi Belajar Siswa Pada Mata Pelajaran Alat dan Mesin Pertanian (PTK Pada Siswa Kelas XI Penyuluh Pertanian SMK Negeri 2 Walenrang)', Jurnal Pendidikan Teknologi Pertanian, 3, pp. 1-14. 